\title{
Therapeutic radionuclides and nuclear data
}

\author{
By S. M. Qaim* \\ Institut für Nuklearchemie, Forschungszentrum Jülich GmbH, D-52425 Jülich, Germany
}

(Received January 3, 2001; accepted in revised form March 12, 2001)

\author{
Therapeutic radionuclide / Decay data / \\ Corpuscular radiation / Endoradiotherapy / \\ Radiation dose / Production data
}

Summary. The nuclear data required for the production and endotherapeutic application of radionuclides are outlined. The three types of therapeutic radionuclides, viz. $\beta^{-}$-emitters, $\alpha$-emitters and Auger electron emitters, are considered and the role of some $\beta^{+}$-emitters in therapy planning is discussed. The status of available data is reviewed.

\section{Introduction}

Radiation therapy has gained an important place in medicine. It is mostly performed using external beams of electrons, $\mathrm{X}$-rays, $\gamma$-rays from radioactive sources $\left(\right.$ e.g. $\left.{ }^{60} \mathrm{Co}\right)$, highenergy $\gamma$-rays from accelerators, or hadrons (neutrons, protons, heavy ions, etc.). The use of electrons and photons constitutes conventional therapeutic practice, and the data needed are well documented. The rationale of hadron therapy and the associated data needs are treated well in this issue (cf. contributions by Jones, Wambersie, Haight, and Chadwick).

In addition to external radiation therapy, some radioisotopes are used internally to achieve the therapeutic effect. This could involve introducing a radioisotope in a given part of the body (e.g.joints, organ, tumour, etc.) either mechanically or via a biochemical pathway. The mechanical introduction takes place through injection of conglomerates or colloids (e.g. in joints) or as solids in the form of seeds or stents. This form of therapy is often known as brachytherapy. The use of a biochemical pathway to deliver a therapeutic radioisotope to a specific organ is termed as endoradiotherapy. This type of radiotherapy is a unique cancer treatment modality. It is systemic and non-invasive. The uptake and retention in the tumour can be assessed with a tracer study prior to administering a therapeutic dose. On the other hand, there are also several associated problems, such as, the exact range of the ionising radiation, the in vivo stability of the radiotherapeutical, the possibility of immuno chemical changes, etc. Many aspects of endoradiotherapy have been discussed [cf. Refs. 1-11]. In this article, the nuclear data aspect is treated in some detail.

\footnotetext{
*E-mail: s.m.qaim@fz-juelich.de
}

\section{Criteria for choice of a radionuclide for therapeutic studies}

The major criteria for the choice of a radionuclide for endotherapeutic use are suitable decay characteristics and suitable biochemical reactivity. As regards decay properties, the desired half-life is between $6 \mathrm{~h}$ and $7 \mathrm{~d}$ and the emitted corpuscular radiation should have a suitable linear energy transfer (LET) value and range in the tissue. The ratio of non-penetrating to penetrating radiation should be high. The daughter should be short-lived or stable. As regards biochemical reactivity, the situation is similar to that for diagnostic radiopharmaceuticals. However, the stability of the therapeutical is demanded over a much longer period than that in the case of a diagnostic pharmaceutical. The basis for successful endoradiotherapy thus incorporates

(i) Good and selective concentration and prolonged retention of the radiotherapeutical in the tumour, and

(ii) Minimum uptake in normal tissue.

As a result of the above mentioned criteria, the choice falls on about 30 radionuclides. Most of them are $\beta^{-}$-emitters but several of them are $\alpha$ - and Auger electron emitters. In recent years a few $\beta^{+}$-emitters have also found some limited therapeutic application.

\section{Radioactive decay data}

The half-life (i.e. the physical half-life) of a radioisotope is important. However, in endoradiotherapy of greater importance is the biological half-life, which determines the retention of the radiotherapeutical in the organ. The physical half-life is generally well known; the biological half-life needs to be determined for each individual system via tracer experiments.

The ranges of various types of emitted corpuscular radiation in the tissue are shown in Fig. 1 [cf. 8,11]. The Auger electrons have a range of about $10 \mu \mathrm{m}$ and can have a therapy effect only if they reach the cell nucleus, $e . g$. by bringing the radioactive source atom to the DNA. The $\alpha$-particles, on the other hand, have a range of about $100 \mu \mathrm{m}$ and can have a therapy effect already if they reach the cell membrane, e.g. by attachment of the $\alpha$-emitter to a receptor ligand. The $\beta^{-}$-particles have ranges of about $1 \mathrm{~mm}$ and more, depending upon their energies. They can lead to therapy effects even if they reach the cell environment. Evidently, achieving the therapy effect with Auger electrons and $\alpha$-particles 


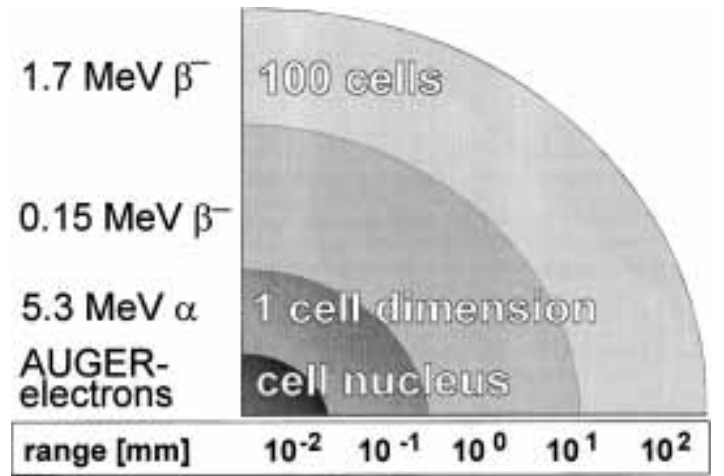

Fig. 1. Correlation between type and energy of corpuscular radiation and the range in tissue (adapted from Refs. $[8,11]$ ).

involves a very subtle approach and demands great skills in biochemistry, radiopharmacology and radiotherapeutical production and application. In the case of $\beta^{-}$-particles, the therapeutic applications have been more straightforward, though not very specific.

The methods of internal dose calculation have received extensive attention and well-known computer codes, known as MIRD codes, are now available. As regards diagnostic radionuclides, calculations are done to keep the radiation dose as low as possible. In the case of therapeutic radionuclides, on the other hand, the dose has to be high enough to achieve the therapeutic effect.

In endoradiotherapy, the radioactive decay data thus play a very important role (see also $[4,8]$ ). In particular, a knowledge of the energy and intensity of the ionising radiation is crucial. The effect of low-energy but high intensity electrons, emitted following EC and IT, is not negligible. For widely used therapeutic radioisotopes therefore all sources of secondary electrons must be taken into account. The accuracy in dosimetry depends on the accuracy of the available decay and biochemical data. In general, the available decay database is extensive [cf. 12,13]. The Auger electron spectra, on the other hand, are often not accurately known.

\section{Production data}

The criteria for the production of therapeutic radioisotopes are generally the same as those for diagnostic radioisotopes, i.e. high radionuclidic purity, high radiochemical purity and high specific radioactivity (cf. contribution by Qaim, this issue). The three types of therapeutic radionuclides, viz. $\beta^{-}$emitters, $\alpha$-emitters and Auger electron emitters, are treated below separately.

\section{1 $\beta^{-}$-emitters}

The number of $\beta^{-}$-emitters of therapeutic relevance is relatively large. The commonly used radionuclides are listed in Table 1. In each case the main decay and production data are outlined. To date, ${ }^{131} \mathrm{I}$ has been most extensively utilized, but in recent years many of the other isotopes listed in Table 1 have been finding enhanced application.

Besides the commonly used $\beta^{-}$-emitters, several other $\beta^{-}$- and $\beta^{+}$-emitters have found isolated therapeutic applications. A few examples of $\beta^{-}$-emitters are: ${ }^{47} \mathrm{Ca}\left(T_{1 / 2}=\right.$ $4.5 \mathrm{~d}),{ }^{47} \mathrm{Sc}\left(T_{1 / 2}=3.4 \mathrm{~d}\right),{ }^{77} \mathrm{As}\left(T_{1 / 2}=1.6 \mathrm{~d}\right),{ }^{105} \mathrm{Rh}\left(T_{1 / 2}=\right.$
$1.5 \mathrm{~d}),{ }^{159} \mathrm{Gd}\left(T_{1 / 2}=18.5 \mathrm{~h}\right),{ }^{161} \mathrm{~Tb}\left(T_{1 / 2}=6.9 \mathrm{~d}\right),{ }^{165} \mathrm{Dy}$ $\left(T_{1 / 2}=2.4 \mathrm{~h}\right),{ }^{166} \mathrm{Dy} \quad\left(T_{1 / 2}=3.4 \mathrm{~d}\right),{ }^{169} \operatorname{Er} \quad\left(T_{1 / 2}=9.4 \mathrm{~d}\right)$, ${ }^{171} \operatorname{Er}\left(T_{1 / 2}=7.5 \mathrm{~h}\right),{ }^{199} \mathrm{Au}\left(T_{1 / 2}=3.1 \mathrm{~d}\right)$, etc. Some of the $\beta^{+}$-emitters occasionally used in endoradiotherapy are: ${ }^{48} \mathrm{~V}$ $\left(T_{1 / 2}=16.9 \mathrm{~d}\right),{ }^{52} \mathrm{Mn}\left(T_{1 / 2}=5.6 \mathrm{~d}\right),{ }^{124} \mathrm{I}\left(T_{1 / 2}=4.2 \mathrm{~d}\right)$, etc. The therapeutic applications of ${ }^{124} \mathrm{I}$ are increasing.

Most of the $\beta^{-}$-emitters are produced in a nuclear reactor, and data are needed on neutron capture, sequential neutron capture, $(n, z)$ processes and fission yields. Some special radionuclides like ${ }^{67} \mathrm{Cu}$ and ${ }^{186} \mathrm{Re}$ are produced using both a reactor and an accelerator.

In a nuclear reactor, the $(n, \gamma)$ process is commonly utilized for production purposes. The excitation function of a typical $(n, \gamma)$ reaction is shown in Fig. 2 [cf. 14]. The major interest is in the low energy region. The specific radioactivity achieved is rather low. In general, it is limited by the cross section of the $(n, \gamma)$ reaction, the isotopic abundance of the target isotope and the neutron flux in the reactor. With a view to enhancing the specific radioactivity, either the $\beta^{-}$-decay daughter of an $(n, \gamma)$-product is used, e.g. ${ }^{110} \mathrm{Pd}(n, \gamma){ }^{111 \mathrm{~m}, \mathrm{~g}} \mathrm{Pd} \rightarrow{ }^{111} \mathrm{Ag}$, or a generator system is developed, e.g. ${ }^{90} \mathrm{Sr} \rightarrow{ }^{90} \mathrm{Y}$ and ${ }^{188} \mathrm{~W} \rightarrow{ }^{188} \mathrm{Re}$. Occasionally an alternative route of production is looked for. This may involve the use of an $(n, p)$ reaction in a fast neutron field or the utilization of a cyclotron. The two aspects are considered individually below.

The $(n, p)$ reaction is occasionally utilized to produce therapeutic radionuclides in the medium and heavy mass regions, besides its use in the light mass region. Two demonstrated examples are ${ }^{67} \mathrm{Zn}(n, p){ }^{67} \mathrm{Cu}$ and ${ }^{89} \mathrm{Y}(n, p){ }^{89} \mathrm{Sr}$. The product yield in a fission neutron spectrum is low, since the threshold of the $(n, p)$ reaction is rather high, i.e. between 2 and $6 \mathrm{MeV}$. The excitation functions of the ${ }^{67} \mathrm{Zn}(n, p){ }^{67} \mathrm{Cu}$ and ${ }^{89} \mathrm{Y}(n, p){ }^{89} \mathrm{Sr}$ reactions, measured radiochemically $[15,16]$, are shown in Fig. 3 . If an intense fast neutron field is used, the cross section averaged over the whole spectrum is much higher than for a fission spectrum. A suitable example is the breakup neutron field, produced by 14-15 MeV deuterons on beryllium [cf. 17]. Since presently available high-intensity commercial machines are capable of providing such fast neutron fields, the production of ${ }^{67} \mathrm{Cu}$ and ${ }^{89} \mathrm{Sr}$ via the respective $(n, p)$ reaction appears very advantageous. Another possibility is the use of a spallation

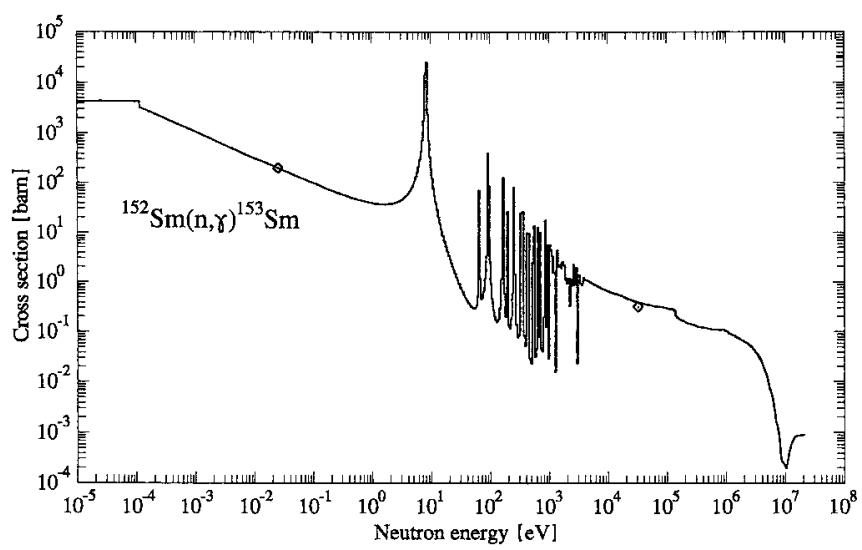

Fig. 2. Excitation function of the ${ }^{152} \mathrm{Sm}(n, \gamma)^{153} \mathrm{Sm}$ reaction. The data were normalized relative to the very precise measurements at the thermal neutron energy $(0.025 \mathrm{eV})$ and at $30 \mathrm{keV}$ (taken from [14]). 
Table 1. Nuclear data relevant to some commonly used therapeutic radionuclides.

\begin{tabular}{|c|c|c|c|c|c|}
\hline $\begin{array}{l}\text { Radio- } \\
\text { nuclide }\end{array}$ & $T_{1 / 2}$ & $\begin{array}{l}E_{\max } \text { of } \\
\text { emitted particle } \\
\text { in } \mathrm{MeV}\end{array}$ & $\begin{array}{l}E_{\gamma} \\
\text { in } \mathrm{keV} \\
\left(I_{\gamma} \text { in } \%\right)\end{array}$ & Production route & $\begin{array}{l}\text { Cross section } \\
\text { in mb or remarks }{ }^{a, b}\end{array}$ \\
\hline \multicolumn{6}{|c|}{$\beta^{-}$-emitters } \\
\hline${ }^{32} \mathrm{P}$ & $14.3 \mathrm{~d}$ & $1.7\left(\beta^{-}\right)$ & & $\begin{array}{l}{ }^{31} \mathrm{P}(n, \gamma) \\
{ }^{32} \mathrm{~S}(n, p)\end{array}$ & $\begin{array}{r}160 \\
70\end{array}$ \\
\hline${ }^{67} \mathrm{Cu}$ & $2.6 \mathrm{~d}$ & $0.6\left(\beta^{-}\right)$ & $185(45)$ & $\begin{array}{l}{ }^{67} \mathrm{Zn}(n, p) \\
\operatorname{RbBr}(p, \text { spall })\end{array}$ & $\begin{array}{l}1.07 \\
1.6 \text { at } 800 \mathrm{MeV} \\
10.0 \text { at } 71 \mathrm{MeV}\end{array}$ \\
\hline${ }^{89} \mathrm{Sr}$ & $50.5 \mathrm{~d}$ & $1.5\left(\beta^{-}\right)$ & & $\begin{array}{l}{ }^{88} \mathrm{Sr}(n, \gamma) \\
{ }^{89} \mathrm{Y}(n, p)\end{array}$ & $\begin{array}{l}5.8 \\
0.31\end{array}$ \\
\hline${ }^{90} \mathrm{Y}$ & $2.7 \mathrm{~d}$ & $2.3\left(\beta^{-}\right)$ & & $\begin{array}{l}{ }^{89} \mathrm{Y}(n, \gamma) \\
{ }^{235} \mathrm{U}(n, f){ }^{90} \mathrm{Sr} \\
{ }^{90} \mathrm{Sr} \rightarrow{ }^{90} \mathrm{Y} \text { generator } \\
(28.6 \mathrm{a})\end{array}$ & $\begin{array}{l}1250 \\
Y_{\text {cum }}: 5.89 \%\end{array}$ \\
\hline${ }^{111} \mathrm{Ag}$ & $7.5 \mathrm{~d}$ & $1.0\left(\beta^{-}\right)$ & $342(6)$ & 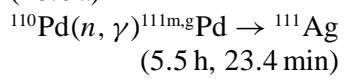 & 733 \\
\hline${ }^{131} \mathrm{I}$ & $8.0 \mathrm{~d}$ & $0.6\left(\beta^{-}\right)$ & $364(81)$ & $\begin{array}{r}\left.{ }^{130} \mathrm{Te}(n, \gamma)\right)^{131 \mathrm{~m}, \mathrm{~g}} \mathrm{Te} \rightarrow{ }^{131} \mathrm{I} \\
(25 \mathrm{~min}, 1.3 \mathrm{~d})\end{array}$ & 230 \\
\hline${ }^{153} \mathrm{Sm}$ & $1.9 \mathrm{~d}$ & $0.8\left(\beta^{-}\right)$ & $103(28.3)$ & $\begin{array}{l}{ }^{235} \mathrm{U}(n, f)^{131} \mathrm{I} \\
{ }^{152} \mathrm{Sm}(n, \gamma)\end{array}$ & $\begin{array}{l}Y_{\text {cum }}=2.84 \% \\
206 \times 10^{3}\end{array}$ \\
\hline${ }^{166} \mathrm{Ho}$ & $1.1 \mathrm{~d}$ & $1.8\left(\beta^{-}\right)$ & $81(6.2)$ & $\begin{array}{l}{ }^{165} \mathrm{Ho}(n, \gamma) \\
{ }^{164} \mathrm{Dy}(n, \gamma){ }^{165} \mathrm{Dy}(n, \gamma){ }^{166} \mathrm{Dy} \\
(2.4 \mathrm{~h}) \\
{ }^{166} \mathrm{Dy} \rightarrow{ }^{166} \text { Ho generator } \\
(3.4 \mathrm{~d})\end{array}$ & $\begin{array}{l}61 \times 10^{3} \\
(2.7 ; 3.5) \times 10^{6}\end{array}$ \\
\hline${ }^{177} \mathrm{Lu}$ & $6.7 \mathrm{~d}$ & $0.5\left(\beta^{-}\right)$ & $208(11)$ & ${ }^{176} \mathrm{Lu}(n, \gamma)$ & $1780 \times 10^{3}$ \\
\hline${ }^{186} \mathrm{Re}$ & $3.8 \mathrm{~d}$ & $1.1\left(\beta^{-}\right)$ & $137(8.5)$ & $\begin{array}{l}{ }^{185} \operatorname{Re}(n, \gamma) \\
{ }^{186} \mathrm{~W}(p, n) \\
{ }^{186} \mathrm{~W}(d, 2 n)\end{array}$ & $\begin{array}{l}114 \times 10^{3} \\
100 \text { at } 10 \mathrm{MeV}^{c} \\
430 \text { at } 13 \mathrm{MeV}^{c}\end{array}$ \\
\hline${ }^{188} \mathrm{Re}$ & $17.0 \mathrm{~h}$ & $2.0\left(\beta^{-}\right)$ & 155 (14.9) & $\begin{array}{l}{ }^{186} \mathrm{~W}(n, \gamma){ }^{187} \mathrm{~W}(n, \gamma){ }^{188} \mathrm{~W} \\
(23.7 \mathrm{~h}) \\
{ }^{188} \mathrm{~W} \rightarrow{ }^{188} \text { Re generator } \\
(69.0 \mathrm{~d})\end{array}$ & $(36 ; 70) \times 10^{3}$ \\
\hline \multicolumn{6}{|c|}{$\alpha$-emitters } \\
\hline $\begin{array}{l}{ }^{211} \mathrm{At} \\
\left({ }^{211} \mathrm{Po}\right)\end{array}$ & $\begin{array}{l}7.2 \mathrm{~h} \\
(0.52 \mathrm{~s})\end{array}$ & $\begin{array}{l}5.9(\alpha) \\
7.5(\alpha)\end{array}$ & & ${ }^{209} \operatorname{Bi}(\alpha, 2 n)$ & 825 at $28 \mathrm{MeV}^{c}$ \\
\hline$\left.{ }^{213} \mathrm{Bi}\right)$ & $46 \mathrm{~min}$ & $\begin{array}{l}5.9(\alpha) \\
1.4\left(\beta^{-}\right) \\
8.3(\alpha)\end{array}$ & $440(16.5)$ & $\begin{array}{l}\text { Gen. }{ }^{225} \mathrm{Ac}(10.0 \mathrm{~d}) \\
\text { (see below) }\end{array}$ & radioactive waste \\
\hline${ }^{225} \mathrm{Ac}$ & $10.0 \mathrm{~d}$ & $5.8(\alpha)$ & $100(1.7)$ & $\begin{array}{l}{ }^{229} \mathrm{Th} \stackrel{\alpha}{\rightarrow}{ }^{225} \mathrm{Ra} \\
(7880 \mathrm{a}) \\
{ }^{225} \mathrm{Ra} \stackrel{\beta^{-}}{\rightarrow}{ }^{225} \mathrm{Ac} \\
(14.8 \mathrm{~d}) \\
{ }^{226} \mathrm{Ra}(p, 2 n) \\
(1600 \mathrm{a})\end{array}$ & radioactive waste \\
\hline \multicolumn{6}{|c|}{ X-ray and Auger electron emitters } \\
\hline${ }^{67} \mathrm{Ga}$ & $3.3 \mathrm{~d}$ & Auger electrons & $93(37)$ & $\begin{array}{l}{ }^{67} \mathrm{Zn}(p, n) \\
{ }^{68} \mathrm{Zn}(p, 2 n)\end{array}$ & $\begin{array}{l}640 \text { at } 11 \mathrm{MeV}^{c} \\
727 \text { at } 20 \mathrm{MeV}^{c}\end{array}$ \\
\hline${ }^{103} \mathrm{Pd}$ & $17.0 \mathrm{~d}$ & Auger electrons & & $\begin{array}{l}{ }^{103} \operatorname{Rh}(p, n) \\
{ }^{n a t} \operatorname{Ag}(p, x)\end{array}$ & $\begin{array}{r}600 \text { at } 10 \mathrm{MeV}^{c} \\
40 \text { at } 28 \mathrm{MeV}^{c}\end{array}$ \\
\hline${ }^{111} \mathrm{In}$ & $2.8 \mathrm{~d}$ & Auger electrons & $245(94)$ & $\begin{array}{l}{ }^{111} \mathrm{Cd}(p, n) \\
{ }^{112} \mathrm{Cd}(p, 2 n)\end{array}$ & $\begin{array}{r}791 \text { at } 12 \mathrm{MeV}^{c} \\
1025 \text { at } 19 \mathrm{MeV}^{c}\end{array}$ \\
\hline${ }^{125} \mathrm{I}$ & $60.1 \mathrm{~d}$ & Auger electrons & $35(6.7)$ & $\begin{array}{c}\left.{ }^{124} \mathrm{Xe}(n, \gamma)\right)^{125} \mathrm{Xe} \rightarrow{ }^{125} \mathrm{I} \\
(16.9 \mathrm{~h})\end{array}$ & $165 \times 10^{3}$ \\
\hline
\end{tabular}

a: Neutron capture data are for thermal neutrons and the $(n, p)$ cross sections are fission neutron spectrum averaged values.

The fission yields are cumulative yields $\left(Y_{\text {cum }}\right)$.

b: For charged particle induced reactions the cross section at a suitable energy is given.

c: For this reaction the full excitation function has been measured.

neutron source, generated by high energy protons on a heavy target. In the spectrum, there is a sufficiently strong fast neutron component (with $E_{\mathrm{n}} \geq 10 \mathrm{MeV}$ ), which is ideally suited for $(n, p)$ reactions. Besides ${ }^{67} \mathrm{Cu}$ and ${ }^{89} \mathrm{Sr}$, several other therapeutic radioisotopes like ${ }^{47} \mathrm{Sc},{ }^{77} \mathrm{As},{ }^{105} \mathrm{Rh},{ }^{153} \mathrm{Sm}$, ${ }^{159} \mathrm{Gd},{ }^{166} \mathrm{Ho},{ }^{177} \mathrm{Lu},{ }^{188} \mathrm{Re}$, etc. could also be produced in fast neutron fields via $(n, p)$ reactions on enriched target isotopes. 


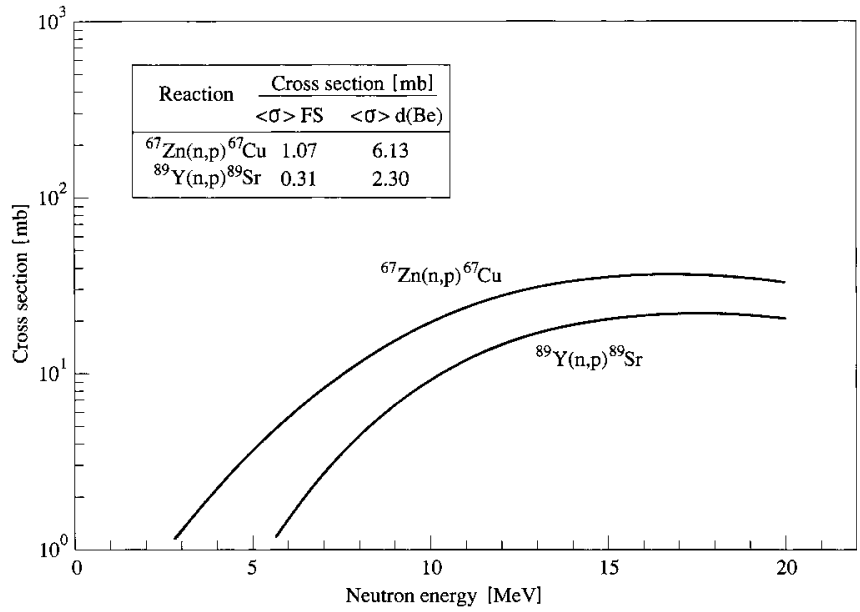

Fig. 3. Excitation functions of ${ }^{67} \mathrm{Zn}(n, p){ }^{67} \mathrm{Cu}$ and ${ }^{89} \mathrm{Y}(n, p){ }^{89} \mathrm{Sr}$ reactions (adapted from Refs. [15,16]). From the given curves the average cross sections $\langle\sigma\rangle$ for $14 \mathrm{MeV} \mathrm{d}(\mathrm{Be})$ breakup neutron spectrum were deduced. Those values as well as the values for a fission spectrum (FS) are given in the insert. The $\langle\sigma\rangle$ values for the $\mathrm{d}(\mathrm{Be})$ breakup neutron spectrum are by a factor of about 6 higher than those for FS.

In recent years attempts have been underway to utilize small and medium-sized cyclotrons to produce some known $\beta^{-}$-emitting therapeutic radionuclides via alternative routes as well as to develop other radionuclides of potential therapeutic interest. Two important examples are furnished by ${ }^{67} \mathrm{Cu}$ and ${ }^{186} \mathrm{Re} .{ }^{67} \mathrm{Cu}$ is almost an ideal therapeutic radionuclide. It is produced via an $(n, p)$ reaction in a nuclear reactor (see above), via the spallation of $\mathrm{RbBr}$ or via the ${ }^{68} \mathrm{Zn}(p, 2 p)$ reaction at a high energy accelerator [cf. 18,19]. A recent study showed [20] that the ${ }^{70} \mathrm{Zn}(p, \alpha){ }^{67} \mathrm{Cu}$ reaction over the proton energy range $E_{\mathrm{p}}=18 \rightarrow 12 \mathrm{MeV}$, using highly enriched ${ }^{70} \mathrm{Zn}$ as target material, can be used to produce ${ }^{67} \mathrm{Cu}$ at a small cyclotron. The radionuclide ${ }^{186} \mathrm{Re}$ is produced generally via the ${ }^{185} \operatorname{Re}(n, \gamma)$-reaction. Since it forms very stable co-ordination compounds (similar to technetium), it has a great therapeutic potential. The main limitation is its specific radioactivity. Two alternative routes making use of the ${ }^{186} \mathrm{~W}(p, n){ }^{186} \mathrm{Re}$ and ${ }^{186} \mathrm{~W}(d, 2 n)^{186} \mathrm{Re}$ reactions are therefore attracting great interest. The excitation functions have been measured [cf. 21-23] and the yields are known (cf. Fig. 4). The yield of ${ }^{186} \mathrm{Re}$ via the $(d, 2 n)$ reac-

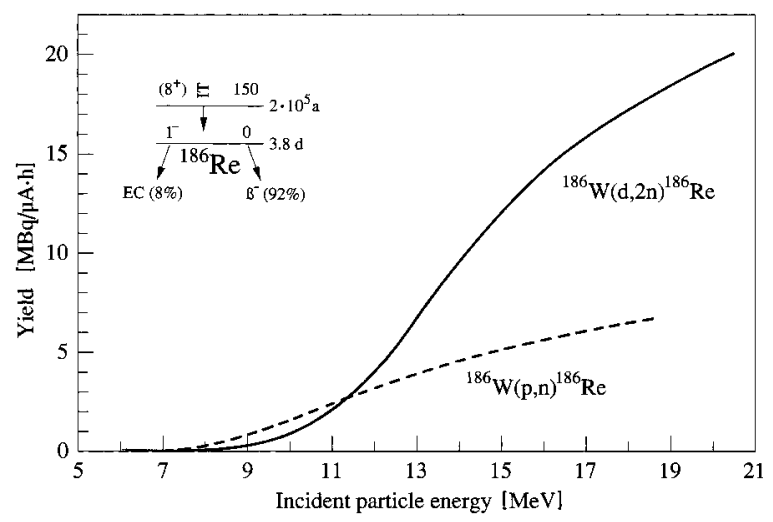

Fig. 4. Calculated integral yields of ${ }^{186} \operatorname{Re}\left(T_{1 / 2}=3.8 \mathrm{~d}\right)$ formed via proton and deuteron induced reactions on ${ }^{186} \mathrm{~W}$. The relatively low yields of ${ }^{186} \mathrm{Re}$ suggest that the very long-lived high-spin isomer is produced in relatively high yields (adapted from [22]). tion at $15 \mathrm{MeV}$ is much higher than via the $(p, n)$ reaction at $19 \mathrm{MeV}$ [cf. 22].

Despite the above mentioned four production approaches to increase the specific activity of a $\beta^{-}$-emitter (viz. use of a $\beta^{-}$-decay daughter of an $(n, \gamma)$-product, development of a generator system, application of an $(n, p)$ reaction or use of a cyclotron), there are a large number of cases where there is no alternative to an $(n, \gamma)$ reaction. Most of those cases refer to rare-earth isotopes which, in recent years, have been attracting enhanced attention [cf. 24] due to their affinity for bone matrix. Fortunately, the $(n, \gamma)$ cross sections in that mass region are quite high, so that the specific radioactivity achieved is not as low as in many other cases. If an enriched target isotope and a higher flux reactor are used, the achievable specific radioactivity may still be enhanced.

\section{$4.2 \alpha$-emitters}

The commonly used $\alpha$-emitting radionuclides are listed in Table 1. ${ }^{211} \mathrm{At}$ is important and is produced via the $(\alpha, 2 n)$ reaction on bismuth and the data are well known [cf. 25]. ${ }^{225} \mathrm{Ac}$ is a promising radioisotope, both in itself and as a generator for ${ }^{213} \mathrm{Bi}$. It is obtained as a decay product of ${ }^{229} \mathrm{Th}$, occurring in the nuclear waste. An interesting production route is the reaction ${ }^{226} \mathrm{Ra}(p, 2 n)^{225} \mathrm{Ac}$ [cf. 26]. Its cross section has hitherto not been measured and constitutes a very challenging task. A few other potentially useful $\alpha$-emitters are ${ }^{149} \mathrm{~Tb}\left(T_{1 / 2}=4.1 \mathrm{~h}\right),{ }^{212} \mathrm{Bi}\left(T_{1 / 2}=1.0 \mathrm{~h}\right),{ }^{223} \mathrm{Ra}$ $\left(T_{1 / 2}=11.4 \mathrm{~d}\right),{ }^{224} \mathrm{Ra}\left(T_{1 / 2}=3.7 \mathrm{~d}\right)$, etc.

The use of $\alpha$-emitting radionuclides in endoradiotherapy has been under review almost ever since the discovery of radioactivity. In recent years it has gained more impetus. It should, however, be pointed out that the application of $\alpha$-emitters demands stringent quality control tests. While working with ${ }^{211} \mathrm{At}$, for example, a very careful check of the irradiation conditions is mandatory. The $\alpha$-particle energy to induce the ${ }^{209} \mathrm{Bi}(\alpha, 2 n)$-reaction is kept at $28.0 \mathrm{MeV}$ otherwise the ${ }^{209} \operatorname{Bi}(\alpha, 3 n)^{210} \mathrm{At}$ reaction would also occur. Its decay product leads to the $\alpha$-emitting ${ }^{210} \mathrm{Po}\left(T_{1 / 2}=138.4 \mathrm{~d}\right)$ and would cause excessive extra radiation dose. The field of radiotherapy with $\alpha$-particles is expected to develop further. Consequently the need for both accurate decay and production data will increase.

\subsection{X-ray and Auger electron emitters}

Some of the X-ray and Auger electron emitters which have found therapeutic use are listed in Table 1. Evidently, both reactors and cyclotrons are utilized for production purposes. However, the cyclotrons appear to have a higher potential since both X-ray and Auger electron emitters are generally neutron deficient.

The radioisotopes ${ }^{67} \mathrm{Ga}$ and ${ }^{111} \mathrm{In}$ are known more as diagnostic radionuclides since they emit suitable $\gamma$-rays. However, their potential as Auger electron emitting therapeutic radionuclides is being increasingly realized. Of particular interest is ${ }^{125} \mathrm{I}$ since it is almost a pure Auger electron emitter and is conveniently attached to a DNA molecule. The radionuclide ${ }^{103} \mathrm{Pd}$ has gained great significance in recent years. The production data were measured 
recently [cf. 27,28] and another study is reaching completion under a Jülich/Debrecen cooperation.

Development work on Auger electron emitters is continuing. The recently studied radionuclide ${ }^{140} \mathrm{Nd}\left(T_{1 / 2}=\right.$ 3.4 d) [cf. 29] is a pure Auger electron emitter. Similarly the radionuclides ${ }^{195 \mathrm{~m}} \mathrm{Pt}\left(T_{1 / 2}=4.0 \mathrm{~d}\right)$ and ${ }^{193 \mathrm{~m}} \mathrm{Pt}\left(T_{1 / 2}=\right.$ $4.3 \mathrm{~d})$ are promising Auger electron emitters. However, the presently used production methods $\left((n, \gamma)\right.$ and $\left(n, n^{\prime} \gamma\right)$ process) give very low yields of the latter two radioisotopes. Since in both cases high spin isomers are involved, the ${ }^{3} \mathrm{He}-$ and $\alpha$-particle induced reactions may be advantageous. In general, Auger electron therapy has a great potential [cf. 30] but calls upon more fundamental work in all related areas.

The radionuclide ${ }^{117 \mathrm{~m}} \mathrm{Sn}\left(T_{1 / 2}=13.6 \mathrm{~d}\right)$ is interesting since here conversion electrons, instead of X-rays and Auger electrons, are effective in palliative therapy. Evidently, all data related to conversion electron emission would be needed for dose calculation. The radionuclide is produced via the $\left(n, n^{\prime} \gamma\right)$-process [cf. 31,32]. An alternative method of production involves the ${ }^{3} \mathrm{He}$ - and $\alpha$-particle induced reactions on In and Cd [33].

\section{Some special considerations in studies relevant to production data}

Most of the special considerations in nuclear data studies related to the production of diagnostic radioisotopes (cf. contribution by Qaim, this issue), such as, the search for alternative production routes, the role of increasing incident particle energy, and the check of isomeric impurities, are valid also for the therapeutic radionuclides. Furthermore, cross section measurements relevant to the formation of pure $\beta^{-}$-emitters and Auger electron emitters are often very challenging since very clean radiochemical separations and thin source preparation are required. The counting methods may involve low-level $\beta^{-}$-counting, X-ray spectrometry or liquid scintillation counting. Thus interdisciplinary techniques are of great significance in these studies.

\subsection{Analogue positron emitters: therapy planning}

A relatively new development in endoradiotherapy with $\beta^{-}$-emitters, initiated at Jülich [cf. 34,35], pertains to internal dosimetry through the use of a $\beta^{+}$-emitting analogue of the therapy radionuclide. A quantitative tracer study via PET, prior to therapeutic application, enables therapy planning and an accurate calculation of the dose distribution during the therapy; such calculations had hitherto been done only empirically. A few analogue $\beta^{+}$-emitters of $\beta^{-}$-emitting therapy radionuclides are: ${ }^{64} \mathrm{Cu}$ for ${ }^{67} \mathrm{Cu},{ }^{83} \mathrm{Sr}$ for ${ }^{89} \mathrm{Sr},{ }^{86} \mathrm{Y}$ for ${ }^{90} \mathrm{Y},{ }^{124} \mathrm{I}$ for ${ }^{131} \mathrm{I}$, etc. Evidently, the production and application of those non-conventional $\beta^{+}$-emitters calls upon considerable nuclear data and other development work.

\section{Status of nuclear data and conclusions}

As discussed above, most of the radionuclides commonly used in endoradiotherapy are $\beta^{-}$-emitters. They are mainly produced in a nuclear reactor and the status of nuclear data is generally good [cf. 36-39]. However, to date no evaluated data file in this respect has been developed. Regarding the $\beta^{-}$- and $\beta^{+}$-emitters which have hitherto found only limited application, or which are of potential interest, the cross section data base varies from case to case. For reactor-produced radionuclides it is good; for cyclotron produced radioisotopes, however, more work may be needed. In particular, an evaluation of the existing data is required. The available information on the established $\alpha$-emitter ${ }^{211} \mathrm{At}$ is good. Similarly the decay and production data of the commonly used Auger electron emitters are well known. For potentially useful $\alpha$-emitters and Auger electron emitters, however, the available information both on decay and production data is often not detailed enough. Since endoradiotherapy is a fast developing field, and new radionuclides emitting the latter two types of corpuscular radiation are being constantly suggested, the need for nuclear data is enhancing. Considerable amount of experimental, theoretical and evaluation work would be necessary to meet those needs. The experimental work is often very challenging since a quantitative measurement of the radioactivity via X-ray spectrometry or Auger electron counting is needed. Theory and evaluations face difficulties since isomeric states with highly converted isomeric transitions are involved. In the latter case, a detailed information on the conversion coefficients is also needed. In short, a concerted effort is called for to build a reliable database relevant to production and application of therapeutic radionuclides.

\section{References}

1. Adelstein, S. J., Kassis, A. I.: Radiobiologic implications of the microscopic distribution of energy from radionuclides. Int. J. Rad. Appl. Instrum. B 14, 165 (1987).

2. Shubiger, P. A., Hasler, P. H. (Eds.): Radionuclides for Therapy. 4th Böttstein Colloquium, Würenlingen/Villigen, Switzerland, June (1986), Editiones (Roche), Basle.

3. Spencer, R. P., Seevers, R. H., Friedman, A. M. (Eds.): Radionuclides in Therapy. CRC Press, Boca Raton (1987).

4. Volkert, W. A., Goeckler, W. F., Erhardt, G. J., Ketering, A. R.: Therapeutic radionuclides: production and decay property considerations. J. Nucl. Med. 32, 174 (1991).

5. Hoefnagel, C. A.: Radionuclide therapy revisited. Eur. J. Nucl. Med. 18, 408 (1991).

6. EANM Task Group Radionuclide Therapy, report 1994: Radionuclide therapy: from pallation to cure.

7. Knapp, Jr., F. F., Mirzadeh, S.: The continuing important role of radionuclide generator systems for nuclear medicine. Eur. J. Nucl. Med. 21, 1151 (1994)

8. Stöcklin, G., Qaim, S. M., Rösch, F.: The impact of radioactivity on medicine. Radiochimica Acta 70/71, 249 (1995).

9. Special Issue: Radiochemistry and Radioimmunotherapy. (Pruett, D. J., Qaim, S. M., Eds.), Radiochim. Acta 79, 71 (1997).

10. Atkins, H. L.: Overview of nuclides for bone pain palliation. Appl. Radiat. Isot. 49, 277 (1998).

11. Lewington, V. J.: Targeted radionuclide therapy for bone metastases. Eur. J. Nucl. Med. 20, 66 (1993).

12. Browne, E., Firestone, R. B.: Table of Radioactive Isotopes. (Shirley, V. S., Ed.), Wiley, London (1986).

13. Nuclear Data Sheets, Periodic issues.

14. Kopecky, J.: Atlas of Neutron Capture Cross Sections, Report INDC (NDS)-362, IAEA, Vienna (1997).

15. Nesaraja, C., Linse, K.-H., Spellerberg, S., Sudár, S., Suhaimi, A., Qaim, S. M.: Excitation functions of neutron induced reactions on some isotopes of zinc, gallium and germanium in the energy range of 6.2 to $12.4 \mathrm{MeV}$. Radiochim. Acta 86, 1 (1999). 
16. Klopries, R. M., Dóczi, R., Sudár, S., Csikai, J., Qaim, S. M.: Excitation functions of some neutron threshold reactions on ${ }^{89} \mathrm{Y}$ in the energy range of 7.8 to $14.7 \mathrm{MeV}$. Radiochim. Acta 76, 3 (1997)

17. Oláh, L., El-Megrab, A. M., Fenyvesi, A., Majdeddin, A. D., Dóczi, R., Semkova, V., Qaim, S. M., Csikai, J.: Investigations on neutron fields produced in ${ }^{2} \mathrm{H}(d, n){ }^{3} \mathrm{He}$ and ${ }^{9} \mathrm{Be}(d, n)^{10} \mathrm{~B}$ reactions. Nucl. Instrum. Meth. Phys. Res. A 404, 373 (1998).

18. Mirzadeh, S., Mausner, L. F., Srivastava, S. C.: Production of nocarrier-added ${ }^{67} \mathrm{Cu}$. Appl. Radiat. Isot. 37, 29 (1986).

19. Schwarzbach, R., Zimmermann, K., Bläuenstein, P., Smith, A., Schubiger, P. A.: Development of a simple and selective separation of ${ }^{67} \mathrm{Cu}$ from irradiated zinc for use in antibody labelling: a comparison of methods. Appl. Radiat. Isot. 46, 329 (1995).

20. Kastleiner, S., Coenen, H. H., Qaim, S. M.: Possibility of production of ${ }^{67} \mathrm{Cu}$ at a small-sized cyclotron via the $(p, \alpha)$-reaction on enriched ${ }^{70} \mathrm{Zn}$. Radiochim. Acta 84, 107 (1999).

21. Shigeta, N., Matsuoka, H., Osa, A., Koizumi, M., Izumo, M., Kobayashi, K., Hashimoto, K., Lambrecht, R. M.: Production method of no-carrier-added ${ }^{186}$ Re. J. Radioanalyt. Nucl. Chem., Articles 205, 85 (1996).

22. Szelecsényi, F., Takács, S., Tárkányi, F., Sonck, M., Hermanne, A.: Study of production possibility of ${ }^{186} \mathrm{Re}$ via the ${ }^{186} \mathrm{~W}(d, 2 n)^{186} \mathrm{Re}$ nuclear reaction for use in radiotherapy. J. Labell. Compd. Radiopharm. 42, 912 (1999).

23. Zhang, X., Li, W., Fang, K., He, W., Sheng, R., Ying, D., Hu, W.: Excitation functions for ${ }^{n a t} \mathrm{~W}(p, x n)^{181-186} \mathrm{Re}$ reactions and production of no-carrier-added ${ }^{186} \mathrm{Re}$ via ${ }^{186} \mathrm{~W}(p, n){ }^{186} \mathrm{Re}$ reaction. Radiochim. Acta 86, 11 (1999).

24. Optimization of production and quality control of therapeutic radionuclides and radiopharmaceuticals, IAEA-TECDOC-1114 (1999).

25. Lambrecht, R. M., Mirzadeh, S.: Cyclotron isotopes and radiopharmaceuticals-XXXV. Astatine-211. Int. J. Appl. Radiat. Isot. 36, 443 (1985)

26. Janssens, W.: E.C. Joint Research Centre, Institute for Transuranium Elements, Karlsruhe, private communication, 1999.

27. Faßbender, M., Nortier, F. M., Schroeder, I. W., van der Walt, T. N.: The production of ${ }^{103} \mathrm{Pd}$ via the ${ }^{n a t} \mathrm{Ag}(p, x)^{103} \mathrm{Pd}$ nuclear process. Radiochim. Acta 87, 87 (1999).

28. Hermanne, A., Snock, M., Fenyvesi, A., Daraban, L.: Study on production of ${ }^{103} \mathrm{Pd}$ and characterisation of possible contami- nants in proton irradiation of ${ }^{103} \mathrm{Rh}$ up to $28 \mathrm{MeV}$. Nucl. Instr. Methods B 170, 281 (2000).

29. Rösch, F., Brockmann, J., Lebedev, N. A., Qaim, S. M.: Production and radiochemical separation of the Auger electron emitter ${ }^{140} \mathrm{Nd}$. Acta Oncologica 727 (2000).

30. Kassis, A. I.: Tumour therapy with low energy electron emitting radionuclides: an overview. Invited paper presented at the 4th Int. Symp. on Radiohalogens, Whistler, Canada, Sept. (2000).

31. Mausner, L. F., Kolsky, K. L., Joshi, V., Srivastava, S. C.: Radionuclide development at BNL for nuclear medicine therapy, Appl. Radiat. Isot. 49, 285 (1998).

32. Knapp, Jr. F. F., Mirzadeh, S., Beets, A. L., O’Doherty, M., Blower, P. J., Verdera, E. S., Gaudiano, J. S., Kropp, J., Guhlke, J., Palmedo, H., Biersack, H.-J.: Reactor-produced radioisotopes from ORNL for bone pain palliation. Appl. Radiat. Isot. 49, 309 (1998).

33. Qaim, S. M., Döhler, H.: Production of carrier-free ${ }^{117 \mathrm{~m}} \mathrm{Sn}$. Int J. Appl. Radiat. Isot. 35, 645 (1984).

34. Rösch, F. Qaim, S. M., Stöcklin, G.: Nuclear data relevant to the production of the positron emitting radioisotope ${ }^{86} \mathrm{Y}$ via the ${ }^{86} \mathrm{Sr}(p, n)$ - and ${ }^{\text {nat }} \mathrm{Rb}\left({ }^{3} \mathrm{He}, x n\right)$-process. Radiochim. Acta 61, 1 (1993).

35. Herzog, H., Rösch, F., Stöcklin, G., Lueders, C., Qaim, S. M., Feinendegen, L. E.: Measurement of pharmacokinetics of yttrium86 radiopharmaceuticals with PET and radiation dose calculation of analogous yttrium-90 radiotherapeutics. J. Nucl. Med. 34, 2222 (1993).

36. Mughabghab, S. F., Divadeenam, M., Holden, N. E.: Neutron Cross Sections, Vol.1. Neutron Resonance Parameters and Thermal Cross Sections. Part A (1981); Mughabghab, S. F.: Part B (1984), Academic Press, New York, USA.

37. McLane, V., Dunford, C. L., Rose, R. F.: Neutron Cross Sections Vol. 2. Neutron Cross Section Curves. Academic Press, New York, USA (1988).

38. Calamand, A.: Cross sections for fission neutron spectrum induced reactions. In: Handbook on Nuclear Activation Cross Sections. Technical Report Series No. 156, IAEA, Vienna (1974), p. 273; for an updated version cf. JEF Report 14. OECD-NEA, Paris, France (1994).

39. Pfennig, G., Klewe-Nebenius, H., Seelmann-Eggebert, W.: Karlsruher Nuklidkarte. Forschungszentrum Karlsruhe, Technik und Umwelt, Karlsruhe (1995). 